University of Nebraska - Lincoln

DigitalCommons@University of Nebraska - Lincoln

4-27-2005

\title{
Dynamic Response Indicators of Heat Stress in Shaded and Non- shaded Feedlot Cattle, Part 2: Predictive Relationships
}

\author{
R. A. Eigenberg \\ University of Nebraska-Lincoln, reigenberg1@Unl.edu \\ T. M. Brown-Brandl \\ USDA-ARS US Meat Animal Research Center, Tami.BrownBrandl@ARS.USDA.GOV \\ John A. Nienaber \\ University of Nebraska-Lincoln, jnienaber2@unl.edu \\ G. Leroy Hahn \\ University of Nebraska-Lincoln, hahn@email.marc.usda.gov
}

Follow this and additional works at: https://digitalcommons.unl.edu/usdaarsfacpub

Part of the Agricultural Science Commons

Eigenberg, R. A.; Brown-Brandl, T. M.; Nienaber, John A.; and Hahn, G. Leroy, "Dynamic Response Indicators of Heat Stress in Shaded and Non-shaded Feedlot Cattle, Part 2: Predictive Relationships" (2005). Publications from USDA-ARS / UNL Faculty. 183.

https://digitalcommons.unl.edu/usdaarsfacpub/183

This Article is brought to you for free and open access by the U.S. Department of Agriculture: Agricultural Research Service, Lincoln, Nebraska at DigitalCommons@University of Nebraska - Lincoln. It has been accepted for inclusion in Publications from USDA-ARS / UNL Faculty by an authorized administrator of DigitalCommons@University of Nebraska - Lincoln. 


\title{
Dynamic Response Indicators of Heat Stress in Shaded and Non-shaded Feedlot Cattle, Part 2: Predictive Relationships
}

\author{
R.A. Eigenberg; T.M. Brown-Brandl; J.A. Nienaber; G.L. Hahn \\ USDA-ARS US Meat Animal Research Center, P.O. Box 166, Clay Center, Nebraska 68933, USA; e-mail of corresponding author: \\ eigenberg@email.marc.usda.gov
}

(Received 19 April 2004; accepted in revised form 2 February 2005; published online 30 March 2005)

\begin{abstract}
Summer heat provides stressful conditions for Bos taurus feeder cattle; in extreme instances these conditions can be fatal. One management option is to provide shade structures for feedlot animals. This study was conducted during the summer of 2001 to compare physiological responses of cattle with shade access or noshade access. Eight steers were selected from a group of 12, and assigned individual pens. Four pens were fitted with shade structures that allowed the steers to choose shade; the remainder had no shade option. The animals were rotated through pen assignments during the summer season. Continuous measures of respiration rate and body temperature were recorded as response variables to the shade treatments. Environmental conditions were monitored for the experimental period. Daytime means and standard errors were $86.0 \pm 0.39$ breaths $\mathrm{min}^{-1}$ for respiration rate shade, and were significantly lower (probability $P<0.05$ ) than respiration rate Noshade of $102.3 \pm 0.36$ breaths $\mathrm{min}^{-1}$. Linear regression fit for daytime data showed the slope for No-shade to be $4.5 \pm 0.15$ breaths $\min ^{-1}$ and $1.5 \pm 0.11$ breaths $\min ^{-1}$ for Shade. Thresholds for humidity and treatment of Shade and No-shade were determined to exist between 25 and $30^{\circ} \mathrm{C}$. Linear regression equations were developed for respiration rate including effects of temperature, humidity, wind speed, and solar radiation for animals in either Shade or No-shade feedlot pens.

Published by Elsevier Ltd on behalf of Silsoe Research Institute
\end{abstract}

\section{Introduction}

Cattle are remarkable in their ability to cope with environmental stressors, and within limits can adjust physiologically, behaviourally, and immunologically to minimise adverse effects (Hahn, 1999). High dry-bulb temperature and humidity, in combination with a solar load and low air movement, can exceed stressor limits with resulting loss of productivity and even death of the animal (Hahn \& Mader, 1997; Gaughan et al., 2000; Lefcourt \& Adams, 1996; Mader et al., 1999). Environmental modification strategies generally focus on reducing either temperature or solar load, or increasing air movement. The use of shade structures can reduce the solar load by as much as 30\% (Bond \& Laster, 1975), and has received attention as an effective way of mediating summer heat loads (Brown-Brandl et al., 2001; Bond \& Laster, 1975; Paul et al., 1998). Shade structures have the advantage of being passive, allowing animals to choose shade as needed, as compared with spraying systems requiring operator control. Recognising the potential severity of a heat stress event, and providing access to stress-reducing measures such as shade structures, can minimise performance and death losses.

Physiological responses to thermal heat loads are dynamic and complex, involving genotype, age, body condition, nutritional, and health status aspects (Hahn, 1999). The animal integrates the environmental conditions and then responds adaptively. A variety of measures can be used to indicate heat stress and can include: behavioural observations, rate of gain, daily feed intake, carcass traits, immune function, core body temperature, and respiration rate (breaths $\min ^{-1}$ ).

Respiration rate is of particular interest as a physiological response, as a large body of research supports a positive correlation between respiration rate and dry-bulb temperature (Ingram \& Mount, 1975; 
Kibler and Brody, 1949; Hahn et al., 1997; Mader et al., 1999; Gaughan et al., 2000; Mitlőhner et al., 2001; Eigenberg et al., 2000). Additionally, increased respiration rate has been associated with increases in solar radiation (Spain \& Spiers, 1996), with increased relative humidity (McLean, 1973) and decreased wind speed (Mader \& Davis, 2002). While individual variability does exist among animals (Hahn et al., 1997), measurement of respiratory rates provides a non-invasive and practical assessment of stress in feedlot cattle due to hot environmental conditions. Respiration rates have the potential to define thresholds for cattle (Hahn et al., 1997). Davis (2001) used panting scores to develop regression equations to extend the use of the temperature humidity index $\left(I_{T H}\right)$ to include effects of wind speed and solar radiation. Specific respiration rate response relationships can provide guidelines for tactical management of cattle in hot weather. A robust estimate of livestock safety is needed that relates environmental parameters to physiological response.

\section{Objectives}

Part I of this study (Brown-Brandl et al., 2005) considered feed and core body temperature response for Shade or No-shade for feedlot cattle. This contribution (Part II) examines respiration rate as the primary physiological response variable to develop predictive relationships in response to dry-bulb temperature, solar radiation, relative humidity, or dew point temperature, and wind speed for Shade and No-shade feedlot cattle.

\section{Materials and methods}

Steer responses were studied at USMARC during eight periods within a 4-month time span, beginning in June and ending in September, 2001. Eight crossbred steers
(1/4 Angus, 1/4 Hereford, 1/4 Pinzgauer, 1/4 Red Poll) were selected from an initial group of 12 , based on weight, and randomly assigned to one of two treatments: Shade or No-shade at the onset of an experimental period (average length is 4.5 days for the eight experimental periods, Table 1). The steers were rotated sequentially through the pens at the onset of each period. They were placed in concrete surfaced pens $(3.6 \mathrm{~m} \times 12 \mathrm{~m})$ that were separated by $3.6 \mathrm{~m}$. Pens were oriented north/south, and were attached to a $122 \mathrm{~m}$ long building located on the north side of the pens; the animals were blocked from access to that building. The treatment of Shade was provided by a self-supporting shade structure constructed of metal tubing and $0.3 \mathrm{~mm}$ thick poly-vinyl shade cloth (100\% shade, grey on top and bottom). Details are shown in Brown-Brandl et al. (2005). The structure covered the south end of the Shade treatment pens to a length of approximately $6 \mathrm{~m}$, and across the full-width of $3.6 \mathrm{~m}$, giving the steers the option of choosing shade. The structure was $3 \mathrm{~m}$ high at the peak, with the east side extending down to a height of $2.4 \mathrm{~m}$, and the west side to a height of $1.8 \mathrm{~m}$. This design provided shade from about 10:00 h to 19:00 h Central Daylight Time (CDT). The feeder and the waterer were located under the shade toward the south end of the pen.

The steers were given feed and water (automatic waterer) adlibitum, with fresh feed given before 09:00 h CDT. Core body temperature was measured using a telemetry system manufactured by HQ, Inc. (9th Street Drive, West Palmetto, FL, USA), consisting of an implantable transmitter and a CorTemp ${ }^{\mathrm{TM}}$ data logger set to $\log$ core body temperature on a $30 \mathrm{~s}$ interval. Temperature transmitters were surgically implanted in the abdominal cavity by a licensed veterinarian (approximately 3 weeks before the experiment started). Respiration response was recorded for a 1-min duration every $15 \mathrm{~min}$, using an automated logging system developed at the USMARC (Eigenberg et al., 2000). The temperature and respiration rate loggers were placed in a pouch on a leather

Table 1

Average and standard error of weather and animal parameters for each of the treatment periods

\begin{tabular}{|c|c|c|c|c|c|c|}
\hline Period & $\begin{array}{c}\text { Year to date, } \\
\text { days }\end{array}$ & $\begin{array}{c}\text { Dry-bulb temperature, } \\
{ }^{\circ} \mathrm{C}\end{array}$ & $\begin{array}{c}\text { Relative humidity, } \\
\%\end{array}$ & $\begin{array}{l}\text { Wind speed, } \\
\qquad m s^{-1}\end{array}$ & $\begin{array}{l}\text { Solar radiation, } \\
\qquad W m^{-2}\end{array}$ & $\begin{array}{l}\text { Weight, } \\
\quad \mathrm{kg}\end{array}$ \\
\hline 1 & $162-167$ & $23 \cdot 52 \pm 0.13$ & $66 \cdot 70 \pm 0.41$ & $4.53 \pm 0.04$ & $340 \cdot 20 \pm 8 \cdot 58$ & $317 \cdot 2 \pm 6 \cdot 0$ \\
\hline 2 & $176-180$ & $25.61 \pm 0.11$ & $63.73 \pm 0.33$ & $4.77 \pm 0.04$ & $320 \cdot 12 \pm 9 \cdot 01$ & $337.9 \pm 7.5$ \\
\hline 3 & $187-191$ & $27.55 \pm 0.11$ & $70.53 \pm 0.42$ & $3.16 \pm 0.03$ & $327.67 \pm 9.20$ & $352.5 \pm 6 \cdot 6$ \\
\hline 4 & $197-206$ & $27.97 \pm 0.08$ & $72.46 \pm 0.28$ & $2.70 \pm 0.02$ & $295.88 \pm 5.81$ & $375.4 \pm 10.5$ \\
\hline 5 & $215-220$ & $28.65 \pm 0.11$ & $65.58 \pm 0.50$ & $2.17 \pm 0.03$ & $273 \cdot 18 \pm 7 \cdot 11$ & $401 \cdot 3 \pm 13 \cdot 1$ \\
\hline 6 & $225-229$ & $22.53 \pm 0.11$ & $79.87 \pm 0.49$ & $2.27 \pm 0.03$ & $266 \cdot 23 \pm 8 \cdot 04$ & $419 \cdot 0 \pm 15 \cdot 3$ \\
\hline 7 & $239-243$ & $23.87 \pm 0.14$ & $76.50 \pm 0.58$ & $1.88 \pm 0.03$ & $248.52 \pm 8.15$ & $440 \cdot 7 \pm 19 \cdot 0$ \\
\hline 8 & $262-264$ & $17 \cdot 94 \pm 0.20$ & $81.85 \pm 0.71$ & $2.68 \pm 0.05$ & $236 \cdot 15 \pm 10 \cdot 78$ & $465 \cdot 2 \pm 23 \cdot 0$ \\
\hline
\end{tabular}

Pen layout data is shown in Brown-Brandl et al. (2005). 
harness that was fitted on each steer. Steers were weighed at the end of each treatment period.

Solar radiation, wind speed, and relative humidity were obtained from the South Central Station of the Automated Weather Data Network (AWDN) weather station located approximately $2.5 \mathrm{~km}$ north of the pens. On-site measures of relative humidity and wind speed were recorded at the research site (located in the centre of the eight pens) every $15 \mathrm{~min}$ for the last four of the eight periods, using a Vantage PRO weather recorder (Davis Instruments, Hayward, CA, USA).

\subsection{Data analysis}

Core body temperature data and respiration rate were compared as physiological responses to thermally stressing environments (Brown-Brandl et al., 2002), with respiration rate being identified as the more responsive measure with less thermal lag between core body temperature and respiration rate. Analysis of core body temperature and daily feed intake were developed in a companion paper (Brown-Brandl et al., 2005). Respiration rate will be used as the primary physiological response in this paper. Respiration rate was tested for the effects of animal, treatment, period, and the interaction of treatment and period, with estimated weight as a covariate using the general linear model procedure of SAS (2000). A correlation was performed between data collected at the site and data collected at AWDN for dry-bulb temperature, relative humidity, and wind speed. A linear regression was generated with respiration rate as the response variable, and dry-bulb temperature as the independent variable for Shade and No-shade, with the data split into daytime (10:00 to 19:00 h) and nighttime (defined by solar radiation equal to zero). Select data were grouped into bins (based on dry-bulb temperature of $2.0^{\circ} \mathrm{C}$ increments forming each bin); data were then segmented into broad groupings for plotting threshold effects based on respiration rate. A linear regression was conducted with respiration rate as the response variable and dry-bulb temperature, humidity effects (either dew point or relative humidity), solar radiation, and wind speed as independent variables.

\section{Results}

\subsection{Data analysis}

Average temperatures and average steer weights for each of the eight periods are shown in Table 1. Respiration rate was tested for the effects of animal, treatment, period, and the interaction of treatment and period, with estimated weight as a covariate using the general linear model procedure of SAS (2000). Respiration rate was significantly (probability $P<0.05$ ) affected by animal, treatment, period, and interaction of period and treatment. Statistical significance of period and treatment/period interaction was anticipated, as it was driven by environmental conditions during the study period. The covariate, weight, was also significant. Weight was nearly a linearly increasing function of time in this study; as such, it was also affected by environmental factors in a manner similar to period.

Table 2 shows treatment means for daytime (10:00 to 19:00 $\mathrm{h}$ when shade was available), and nighttime (radiation $=0$ ). Overall averages differed significantly for the treatments, and daytime respiration rate for the No-shade treatment was significantly higher than for the Shade steers. Nighttime respiration rates were statistically different $(P<0 \cdot 05)$, with the No-shade treatment showing a lower respiration rate, possibly due to nighttime radiation. These results compare well with a similar experiment conducted in 2000 (Brown-Brandl et al., 2001), also shown in Table 2.

Regression equations for respiration rate and drybulb temperature were developed using all data, and

Table 2

Treatment means and standard errors for respiration rate in breaths per minute for daytime (10:00 to 19:00 h when shade was available), nighttime (radiation $=0$ ), and for all data combined

\begin{tabular}{|c|c|c|c|c|}
\hline \multirow{3}{*}{ Period } & \multicolumn{4}{|c|}{ Respiration rate, breaths $\mathrm{min}^{-1}$} \\
\hline & \multicolumn{2}{|c|}{ Current study } & \multicolumn{2}{|c|}{2000 Study* $^{*}$} \\
\hline & Shade & No-shade & Shade & No-shade \\
\hline $\begin{array}{l}\text { Daytime } \\
\text { Nighttime } \\
\text { Overall }\end{array}$ & $\begin{array}{l}86 \cdot 0 \pm 0 \cdot 39^{\mathrm{a}} \\
62 \cdot 6 \pm 0.43^{\mathrm{a}} \\
74 \cdot 3 \pm 0 \cdot 29^{\mathrm{a}}\end{array}$ & $\begin{array}{r}102 \cdot 3 \pm 0.36^{\mathrm{b}} \\
60 \cdot 2 \pm 0 \cdot 39^{\mathrm{b}} \\
81.2 \pm 0.27^{\mathrm{b}}\end{array}$ & $\begin{array}{l}85 \cdot 9 \pm 2 \cdot 3 \\
55 \cdot 3 \pm 1 \cdot 2 \\
72 \cdot 0 \pm 1 \cdot 5\end{array}$ & $\begin{array}{r}103 \cdot 8 \pm 2 \cdot 3 \\
62 \cdot 7 \pm 1 \cdot 2 \\
81 \cdot 3 \pm 1 \cdot 5\end{array}$ \\
\hline
\end{tabular}

\footnotetext{
*Brown-Brandl et al. (2001).

${ }^{\mathrm{a}, \mathrm{b}}$ Numbers within a row with differing superscripts are significantly different (probability $P<0 \cdot 05$ ), as tested by LSMEANS using the PDIFF option (SAS, 2000).
} 
daytime data (10:00 to 19:00 h when shade was available), with coefficients shown in Table 3. Comparing all data showed that respiration rate increased at a rate of 5.4 breaths $\min ^{-1}{ }^{\circ} \mathrm{C}^{-1}$ for the No-shade animals. The rate of change of respiration rate for daytime data was 4.5 breaths $\min ^{-1 \circ} \mathrm{C}^{-1}$ for No-shade. Table 3 also compares results of the current study with a study conducted in 2000 (Brown-Brandl et al., 2001). The two studies compared favourably; the overall Noshade response was 5.4 breaths $\min ^{-1}{ }^{\circ} \mathrm{C}^{-1}$ for current study versus 4.6 breaths $\min ^{-1}{ }^{\circ} \mathrm{C}^{-1}$ for 2000 study, while the daytime No-shade response was 4.5 breaths $\min ^{-1}{ }^{\circ} \mathrm{C}^{-1}$ for current study versus 4.4 breaths $\min ^{-1}{ }^{\circ} \mathrm{C}^{-1}$ for 2000 study.

A correlation was performed between data from AWDN and the shade study site for wind speed, dry-

Table 3

Regression coefficients $\left(R_{R}=b_{0}+b_{1} t_{d b}\right.$, [where $t_{d b}$ is dry-bulb temperature, $R_{R}$ is respiration rate, and $b_{0}$ and $b_{1}$ are linear regression coefficients]) based on all animal responses to describe differences in respiration rate in unshaded conditions to dry-bulb temperature for all data, and daytime (10:00 to 19:00 h); $R^{2}$, coefficient of determination

\begin{tabular}{lccc}
\hline & Regression & \multicolumn{2}{c}{ Mean \pm SD } \\
\cline { 3 - 4 } & coefficients & Current study & 2000 Study \\
\hline Overall & $b_{0}$ & $-68 \cdot 0 \pm 3 \cdot 2$ & $-40 \cdot 4 \pm 9 \cdot 3$ \\
& $b_{1}$ & $5.4 \pm 0 \cdot 11$ & $4.6 \pm 0.4$ \\
& $R^{2}$ & 0.32 & 0.42 \\
Daytime & $b_{0}$ & $-34.2 \pm 4.7$ & $-31.8 \pm 27.5$ \\
(10:00-19:00 h) & $b_{1}$ & $4.5 \pm 0.15$ & $4.4 \pm 0.9$ \\
& $R^{2}$ & 0.21 & 0.19 \\
\hline
\end{tabular}

*Bown-Brandl et al. (2001). bulb temperature, and relative humidity for the last four of the eight periods, when on-site data was available. Both dry-bulb temperature and relative humidity correlate well with values for the correlation coefficient $R$ of 0.99 and 0.95 , respectively; however, wind speed is not as well correlated with value for $R$ of about 0.82 . This is not unexpected, with the study site location situated between two large structures that affect air movement. On-site wind data were used when available.

\subsection{Plots}

The overall conditions were summarised on a $24 \mathrm{~h}$ basis for the experimental periods and plotted in Fig. 1 . The composite of conditions showed wind speed tracking dry-bulb temperature with a peak at about 16:00 h CDT, and both reaching minimums at about 06:00 CDT; wind speed had an additional low point at 22:00 h CDT. The dry-bulb temperature is relatively flat during daylight hours, peaking slightly at twilight and then dipping to a low at 06:00 h CDT. By definition, relative humidity mirrors the temperature curve, falling when temperatures were highest. Solar radiation peaks about 14:00 $\mathrm{h}$ CDT as expected for the geographical location of the study site. Figure 2 displays respiration rate and core body temperature for No-shade data, shown with dry-bulb temperature and solar radiation summarised on a $24 \mathrm{~h}$ basis for the entire data set. The resting animal's core body temperature typically falls from about midnight till dawn, while respiration rate is nearly constant over that same period (Fig. 2). Respiration rate peaked earlier in the day than core body temperature by about $2 \mathrm{~h}(15: 00 \mathrm{~h}$ versus 17:00 $\mathrm{h} C D T)$. Both declined rapidly after 18:00 h CDT. Respiration

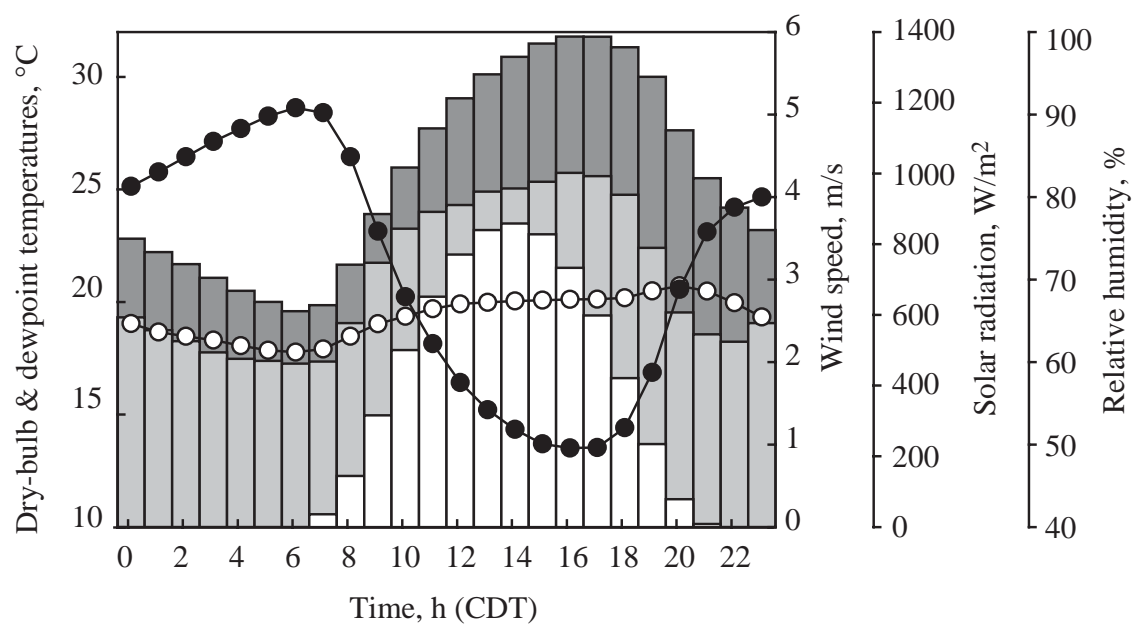

Fig. 1. Summary of weather parameters on a $24 \mathrm{~h}$ basis (midnight $=0.0$ ); average standard error for dry-bulb temperature was $0.13{ }^{\circ} \mathrm{C}$, relative humidity $0.47 \%$, wind speed $0.03 \mathrm{~m} \mathrm{~s}^{-1}$, and solar radiation $8.34 \mathrm{Wm}^{-2} ;(\square)$, dry-bulb temperature; ( $\square$ ), wind speed; (口), solar radiation; (-०), dew-point temperature; (-), relative humidity; CDT, central daylight time 


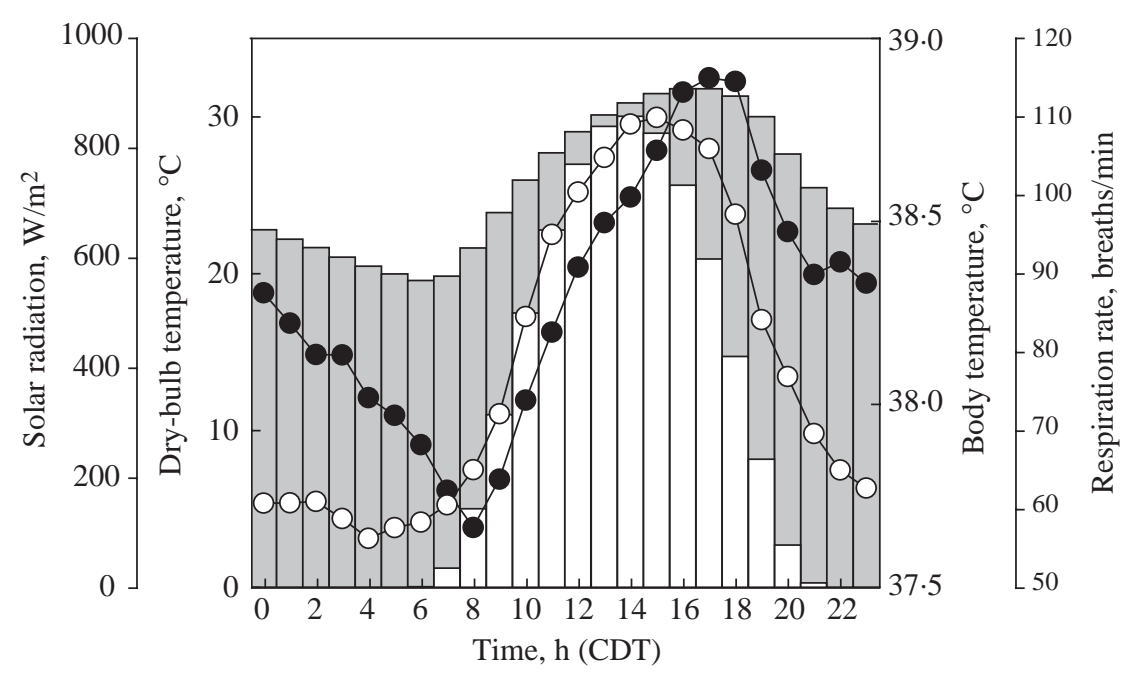

Fig. 2. Respiration rate (-o-) and core body temperature (-) for No-shade data shown with dry-bulb temperature (ㅁ) and solar radiation (口) summarised on a $24 \mathrm{~h}$ basis (midnight $=0.0$ ); average standard error for dry-bulb temperature was $0 \cdot 13^{\circ} \mathrm{C}$, solar radiation $8.34 \mathrm{Wm}^{-2}$, respiration rate 0.85 breaths $\min ^{-1}{ }^{\circ} \mathrm{C}^{-1}$, and core body temperature $0.02{ }^{\circ} \mathrm{C}$; CDT, central daylight time

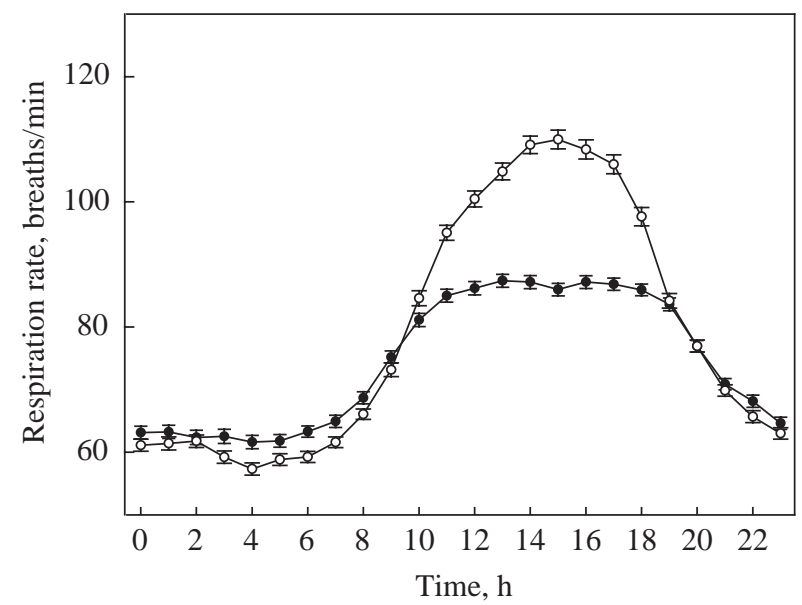

Fig. 3. Respiration rates for Shade (--) and No-shade (-o-) summarised on a $24 \mathrm{~h}$ basis (midnight $=0$ ), with standard errors as shown

rate for the Shade and No-shade treatments are shown in Fig. 3. The effect of shade is evident from about 10:00-19:00 h CDT, with a 30 breaths $\mathrm{min}^{-1}$ difference occurring at about 15:00 h CDT.

Thresholds for treatment and humidity effects were observed by grouping data into bins (with a dry-bulb temperature change of $2 \cdot 0^{\circ} \mathrm{C}$ forming each bin). The dew point temperature data (No-shade only) were separated by first determining the median value $\left(19 \cdot 1^{\circ} \mathrm{C}\right)$ of the dew point temperature data, and then splitting into a high (dew point temperature $>19 \cdot 1{ }^{\circ} \mathrm{C}$ ) and low (dew point temperature $\leqslant 19 \cdot 1^{\circ} \mathrm{C}$ ) range. The resulting plot is shown in Fig. 4. Plots for both low dew

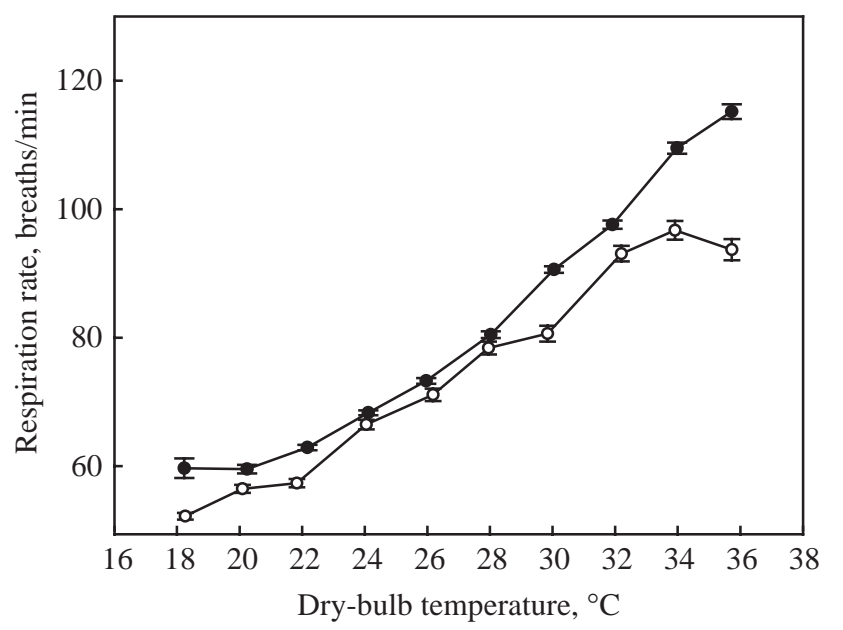

Fig. 4. Respiration rate as a function of dry-bulb temperature for two ranges of dew points for steers without shade, with standard errors as shown: (-O-), dew point of $\leqslant 19 \cdot 1^{\circ} \mathrm{C}$; (-), dew-point of $>19 \cdot 1^{\circ} \mathrm{C}$

point temperature and high dew point temperature are parallel initially. As temperature increases, the low dew point temperature curve crosses the high dew point temperature curve at about $27^{\circ} \mathrm{C}$. The dew point temperature curves indicate that for temperatures above $27^{\circ} \mathrm{C}$, a higher dew point temperature brings on higher respiration rates when compared to the lower dew point temperature conditions. Figure 5 is a comparison of Shade and No-shade; the two curves are nearly coincident at low temperatures until they diverge around $26^{\circ} \mathrm{C}$. The Shade respiration rate begins to plateau at $30^{\circ} \mathrm{C}$ and beyond. At about $26^{\circ} \mathrm{C}$ the No-shade trace trends upward with increasing dry-bulb temperature, 


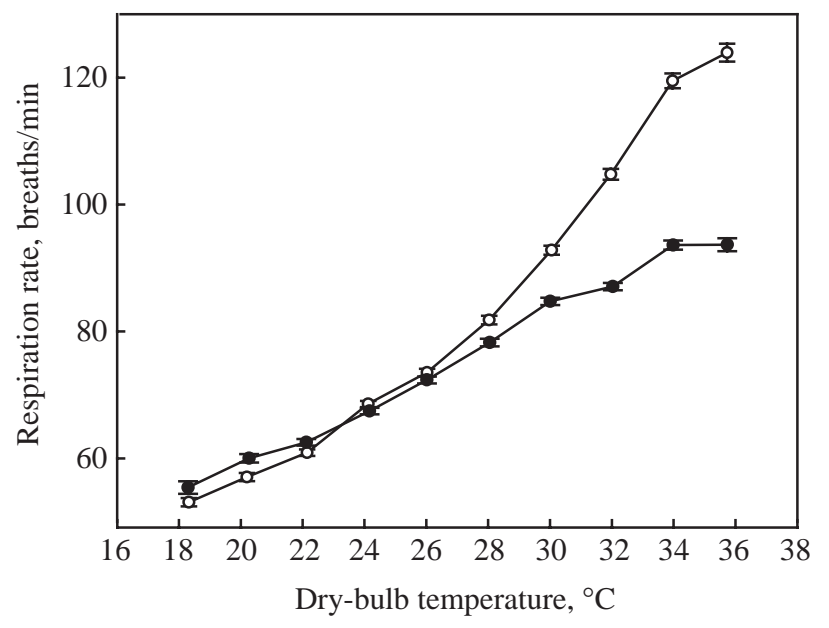

Fig. 5. Respiration rate as a function of dry-bulb temperature and treatment, with standard errors as shown: (-o-), No-shade; (-) ), Shade

giving evidence to the physiological response to solar radiation. These two figures demonstrate a threshold effect that occurs between 25 and $30^{\circ} \mathrm{C}$, which is similar to the thresholds observed by Hahn (1999) and Hahn et al. (1997).

\subsection{Regression analysis}

The above data suggest a basis for a predictive relationship among the variables of dry-bulb temperature, humidity (measured by dew point temperature or relative humidity), solar radiation, and wind speed, with a dry-bulb temperature breakpoint of $25^{\circ} \mathrm{C}$. A linear regression was performed on the basis of this premise, with respiration rate as the response variable and drybulb temperature, relative humidity or dew point temperature, solar radiation, and wind speed as independent variables, and temperatures greater than $25^{\circ} \mathrm{C}$, with results shown as Eqns (1) and (2).

For No-shade, $t_{d b}>25^{\circ} \mathrm{C}$ :

$$
\begin{array}{r}
R_{R}=2 \cdot 8 t_{d b}+2.4 t_{d p}-1.5 v_{w}+0.038 r_{s}-52.8 \\
R_{R}=5 \cdot 1 t_{d b}+0.58 H_{R}-1.7 v_{w}+0.039 r_{s}-105.7
\end{array}
$$

In Eqns (1) and (2), $R_{R}$ is the respiration rate in breaths $\min ^{-1}, t_{d b}$ is the dry-bulb temperature in ${ }^{\circ} \mathrm{C}, t_{d p}$ is the dew point in ${ }^{\circ} \mathrm{C}, H_{R}$ is the relative humidity in percent, $v_{w}$ is wind speed in $\mathrm{m} \mathrm{s}^{-1}$, and $r_{s}$ is solar radiation in $\mathrm{W} \mathrm{m}^{-2}$. Both Eqns (1) and (2) have a value for the coefficient of determination $R^{2}$ of 0.45 .

Equations (1) (based on dew point temperature) and (2) (based on relative humidity) generate an estimate of respiration rate for cattle when temperatures exceed
Table 4

The relative contribution (based on the standardised estimate generated by PROC REG of SAS, 2000) of each of the variables in Eqn (1) (dry-bulb temperature $>25^{\circ} \mathrm{C}$ )

\begin{tabular}{lc}
\hline Parameter & Contribution, \% \\
\hline Dew point temperature & 8.9 \\
Dry-bulb temperature & 32.2 \\
Wind speed & 5.7 \\
Solar radiation & 51.4 \\
Weight & 1.9 \\
\hline
\end{tabular}

$25^{\circ} \mathrm{C}$ under No-shade conditions. All variables of the multivariate linear regression were significant $(P<0 \cdot 05)$. The relative contribution (based on the standardised estimate generated by PROC REG of SAS) of each of the variables in Eqn (1) are shown in Table 4. The table shows solar radiation and dry-bulb temperature to be the greatest contributors to the dynamics, with 51.4 and $32.2 \%$ respectively. Dew point and wind speed contribute 8.9 and $5.7 \%$, with the contribution of steer weight to overall respiration rate dynamics to be less than $2 \%$. Based on this low contribution and the confounding effects with time, weight was not included in the respiration rate predictive equation.

Equation (2) was implemented in a spreadsheet, as well as Eqn (3) for temperature humidity index $I_{T H}$ (Hahn, 1999):

$$
I_{T H}=0 \cdot 8 t_{d b}+\left(t_{d b}-14.4\right) H_{R} / 100+46.4
$$

In Eqn (3), $I_{T H}$ is the temperature humidity index, $H_{R}$ is relative humidity in percent, and $t_{d b}$ is dry-bulb temperature in ${ }^{\circ} \mathrm{C}$. Dry-bulb temperature, relative humidity, wind speed, and solar radiation were used as independent variables to generate estimates for respiration rate and $I_{T H}$. Temperature humidity index values were generated on the spreadsheet for a range of temperatures $\left(25-40^{\circ} \mathrm{C}\right)$ and humidity $(30-50 \%)$, with corresponding estimates for respiration rates. Based on the spreadsheet output, a change of one unit of $I_{T H}$ corresponded to a 4.0 breaths $\mathrm{min}^{-1}$ change in respiration rate. The 4.0 scale factor was used to generate an estimate of the impact that solar radiation and wind speed may have on temperature humidity index, and is shown in Table 5. The impact of solar radiation is estimated to result in a 0.97 change of $I_{T H}$ for every $100 \mathrm{~W} \mathrm{~m}^{-2}$ change in solar radiation. The estimated impact on wind speed indicates a -0.42 change in $I_{T H}$ for every $1 \mathrm{~m} \mathrm{~s}^{-1}$ increase in wind speed. Table 5 shows that effects of dry-bulb temperature and relative humidity based on the current study compare well to effects predicted by the $I_{T H}$ equation. 
Table 5

Comparison of temperature humidity index $I_{T H}$ equivalent contribution based on current study

\begin{tabular}{lccc}
\hline & $\begin{array}{c}\text { Change in } \\
\text { parameter value }\end{array}$ & $I_{T H}$ & $\begin{array}{c}\text { Current study } \\
I_{T H} \text { equivalent } \\
\text { adjustment }\end{array}$ \\
\hline Temperature & $10{ }^{\circ} \mathrm{C}$ & 11.0 & 12.7 \\
Humidity & $10 \%$ & 1.2 & 1.4 \\
Solar radiation & $100 \mathrm{~W} \mathrm{~m}^{-2}$ & & 0.97 \\
Wind speed & $1 \mathrm{~m} \mathrm{~s}^{-1}$ & & -0.42 \\
\hline
\end{tabular}

${ }^{*}$ Corrections based on averages over $25-40{ }^{\circ} \mathrm{C}$ and $30-50 \%$ relative humidity for the $I_{T H}$ equation resulting in a change in respiration rate that corresponds to a four-fold change in temperature humidity index.

Table 6

Temperature humidity index $I_{T H}$ thresholds related to respiration rate based on Eqn (2) for the assumptions of solar radiation of $800 \mathrm{Wm}^{-2}$ and wind speed of $0 \mathrm{~m} \mathrm{~s}^{-1}$; relative humidity ranges from 30 to $50 \%$ and dry-bulb temperature from 25 to $40{ }^{\circ} \mathrm{C}$

\begin{tabular}{lcc}
\hline Threshold & \multicolumn{1}{c}{$I_{T H}$} & Respiration rate, breaths min $^{-1}$ \\
\hline Normal & $\leqslant 74 \cdot 0$ & $\leqslant 90$ \\
Alert & $>74-\leqslant 79$ & $90-110$ \\
Danger & $>79-\leqslant 84$ & $110-130$ \\
Emergency & $>84$ & $\geqslant 130$ \\
\hline
\end{tabular}

The spreadsheet was also used to establish stress thresholds based on respiration values. The spreadsheet was run using the equation for $I_{T H}$, and assuming a value of $800 \mathrm{~W} \mathrm{~m}^{-2}$ for solar radiation and $0 \mathrm{~m} \mathrm{~s}^{-1}$ for wind speed, with relative humidity ranging from 30 to $50 \%$ and dry-bulb temperature from 25 to $40{ }^{\circ} \mathrm{C}$. Table 6 shows respiration rate values that would correspond to $I_{T H}$ thresholds for these conditions. The derived values, based on Eqn (2) for No-shade cattle, need to be tested and further data collected, but may serve as estimates of potentially stressful conditions for cattle under hot conditions.

\section{Conclusions}

In this study, cattle with No-shade had daytime respiration rates that were on average 16 breaths $\min ^{-1}$ higher than cattle that had shade access. Dry-bulb temperature increases resulted in respiration rate increases that were about three times higher for No-shade animals, compared to animals having shade for daytime conditions. Thresholds were observed to occur for effects of shade and effects of humidity at dry-bulb temperature between 25 and $30^{\circ} \mathrm{C}$. A linear regression equation was developed to estimate respiration rate that includes effects of dry-bulb temperature, dew point temperature or relative humidity, solar radiation, and wind speed for temperatures above $25^{\circ} \mathrm{C}$. Thresholds were developed to relate the temperature humidity index $I_{T H}$ to respiration rates to estimate thermal status of livestock. Future work using respiration rates and panting scores should refine these values for better parameter estimates for a model useful to the cattle feedlot industry.

\section{References}

Bond T E; Laster D B (1975). Influence of shading on production of midwest feedlot cattle. Transactions of the American Society Agricultural Engineers, 18, 957-959

Brown-Brandl T M; Eigenberg R A; Hahn G L; Nienaber J A (2001). Correlations of respiration rate, core body temperatures, and temperatures for shaded and non-shaded cattle. Proceedings, Sixth International Livestock. Environment Symposium, pp 448-454. American Society Agricultural Engineers, Louisville, Kentucky

Brown-Brandl T M; Eigenberg R A; Hahn G L; Nienaber J A; Mader T L; Spiers D E; Parkhurst A M (2002). Dynamic responses of feeder cattle to simulated heat waves. ASAE Paper No. 024051

Brown-Brandl T M; Eigenberg R A; Nienaber J A; Hahn G L (2005). Dynamic response indicators of heat stress in shaded and non-shaded feedlot cattle-part I: analysis of indicators. Biosystems Engineering, doi:10.1016/j.biosystemseng.2004.12.006

Davis M S (2001). Management strategies to reduce heat stress in feedlot cattle, 267pp. Dissertation, University of Nebraska-Lincoln, NE, December, 2001

Eigenberg R A; Hahn G L; Nienaber J A; Brown-Brandl T (2000). Development of a respiration rate monitor for cattle. Transactions of the American Society Agricultural Engineers, 43(3), 723-728

Gaughan J B; Holt S M; Hahn G L; Mader T L; Eigenberg R (2000). Respiration rate - is it a good measure of heat stress in cattle?. Asian-Australian Journal Animal Science, 13(Supp C), 329-332

Hahn G L (1999). Dynamic responses of cattle to thermal heat loads. Journal Animal Science, 77(Supp 2), 10-12

Hahn G L; Mader T L (1997). Heat waves in relation to thermoregulation, feeding behavior and mortality of feedlot cattle. Proceedings, 5th International Livestock Environment Symposium, pp 563-571. ASAE SP01-97, American Society Agricultural Engineers, Minneapolis, MN

Hahn G L; Parkhurst A M; Gaughan J B (1997). Cattle respiration rate as a function of ambient temperature. ASAE Paper No. MC97-121

Ingram D L; Mount L E (1975). Heat exchange between animal and environment. In: Man and Animals in Hot Environments (Ingram D L; Mount L E, eds), pp 5-23. SpringerVerlag, New York, Heidelberg, Berlin

Kibler H H; Brody S (1949). Influence of temperature, 50 to 5F and 50 to $95 \mathrm{~F}$, on heat production and cardiorespiratory activities in Brahman, Jersey and Holstein cows. Research Bulletin 450, Environmental Physiology and Shelter Engineering Series VII, Missouri Agricultural Experiment Station. University of Missouri, Columbia, MO 
Lefcourt A M; Adams W R (1996). Radiotelemetry measurement of body temperatures of feedlot steers during summer. Journal Animal Science, 74, 2633-2640

Mader T L; Dahlquist J M; Hahn G L; Gaughan J B (1999). Shade and wind barrier effects on summertime feedlot cattle performance. Journal Animal Science, 77, 2065-2072

Mader T L; Davis M S (2002). Wind speed and solar radiation corrections for the temperature-humidity index. Proceedings, 15th Conference on Biometeorology and Aerobiology, Joint with 16th International Congress on Biometeorology, 10-28-2, Kansas City, MO

McLean J A (1973). Loss of heat by evaporation. In: Heat Loss from Animals and Man. (Monteith J L; Mount L E, eds), pp 19-31. Proceedings 20th Easter School in Agricultural Science, Butterworths, London
Mitlőhner F M; Morrow J L; Dailey J W; Wilson S C; Galyean M L; Miller M F; McGlone J J (2001). Shade and water misting effects on behavior, physiology, performance, and carcass traits of heat-stressed feedlot cattle. Journal Animal Science, 79, 2327-2335

Paul R M; Turner L W; Larson B T (1998). Effects of shade on tympanic temperatures and production parameters of grazing beef cows. ASAE Paper No. 984029

SAS Institute Inc. (2000). SAS System for Windows, Version 8. SAS Institute Inc., Cary, NC

Spain J N; Spiers D E (1996). Effects of supplemental shade on thermoregulatory response of calves to heat challenge in a hutch environment. Journal Dairy Science, 79, 639-646 